\title{
PROPOSTA DE FRAMEWORK DE GERENCIAMENTO DE RISCOS ORGÂNICOS APLICADO À LOGÍSTICA
}

\author{
Sérgio Luiz Hoeflich \\ Universidade de São Paulo \\ Programa de Engenharia Elétrica \\ shoeflich@ig.com.br \\ Maurício Fontoura Blos, D.Eng \\ Universidade de São Paulo \\ Programa de Engenharia Mecatrônica \\ blos31@hotmail.com
}

Aureo Emanuel Pasqualeto Figueiredo, MSc

Universidade São Paulo

Programa de Engenharia Elétrica

aureo@gmail.com

Eduardo Mário Dias, DSc

Universidade de São Paulo

Programa de Engenharia Elétrica

gaesi@pea.usp.br

\begin{abstract}
Resumo
O artigo apresenta um framework da gestão do risco aplicado ás cadeias de suprimento. Contém diversas definições relativas às diferentes abordagens do risco logístico, cujo objetivo é propor uma nomenclatura aplicada à gestão de riscos orgânicos. $\mathrm{O}$ uso deste método diferenciado de análise de risco aplicado à cadeia de suprimentos conduz à prática de um desempenho sustentado, provendo segurança as operações logísticas, nos diversos níveis das organizações. Apresenta as diferentes ferramentas e normas de gestão de riscos nas organizações que inseridas numa abordagem orgânica sendo sistematizadas pelo framework para orientar os gestores na analise de riscos logísticos.
\end{abstract}

Palavras-Chaves: Gerenciamento de Riscos; Logística; Riscos Orgânicos; Framewok.

\begin{abstract}
The article presents a framework of risk management concerns to supply chains. Contains several definitions for the different approaches of the logistic risk, whose guide to propose an applied risk management of organic nomenclature. Using this distinctive method of risk analysis applied to the supply chain leads to the practice of sustained performance, providing security logistics operations at various levels of the organizations. Presents the different tools and standards for risk management in organizations embedded in an organic and systematic approach by the framework to guide managers in the analysis of logistics risks.
\end{abstract}

Keywords: $\quad$ Risk Management; Logistic, Organic Risk; Framework.

\section{INTRODUÇÃO}

O risco é inerente a qualquer atividade humana, já que toda atividade humana tem uma dose de incerteza a ela associada. O homem, os grupos humanos e as sociedades vêm utilizando diversos métodos experimentais para lidar com as incertezas. Atualmente esses métodos são basicamente de caráter técnico e de caráter financeiro. A implantação de novas metodologias de análise dos riscos não financeiros gerou demanda pelo desenvolvimento de 
procedimentos de caráter gerencial.

Risco, segundo HOUAISS (1994) significa "perigo ou possibilidade de perigo", ou ainda, "a possibilidade de perda ou responsabilidade pelo dano, situação em que há possibilidades mais ou menos previsíveis de perda ou ganho (e.g. em um jogo de azar ou em uma decisão de investimento). É uma consequência da decisão livre e consciente de expor-se a uma situação na qual se luta pela realização do bem, havendo a possibilidade de dano ou perda. Conforme PIEPER (1960), "entende-se por dano toda a violação da incolumidade natural contrária à nossa vontade, tudo o que contraria a nossa vontade, tudo o que é de qualquer modo negativo, tudo o que magoa e prejudica, atemoriza e oprime". O dano ou ferimento mais profundo e extremo é a morte. "E mesmo os ferimentos ou danos não mortais são imagem da morte". Portanto, o ser humano que possui a virtude cardeal da fortaleza expõe-se ao perigo da morte por causa do bem. E só quem é prudente vê a realidade como ela é objetivamente, enquanto o justo - aquele que dá a cada um o que lhe é devido - pode ser forte.

O termo risco é proveniente da palavra riscare, em italiano, que significa ousar (to dare, em inglês). No sentido de incerteza é derivada do latim risicu e riscu e deve ser interpretada como um conjunto de incertezas encontradas quando ousamos fazer algo, e não apenas como um problema. Assim, costuma-se entender "risco" como possibilidade de "algo não dar certo", mas o conceito atual de risco envolve a quantificação e qualificação da incerteza, tanto no que diz respeito às "perdas" como aos "ganhos", com relação ao rumo dos acontecimentos planejados, seja por indivíduos ou por organizações. Desta forma e segundo a IMO (2006) o risco é uma consequência da decisão livre e consciente de expor-se a uma situação na qual se luta pela realização do bem havendo a possibilidade de dano ou perda.

Sempre que olhamos para o futuro, temos que lidar com incertezas. BERNSTEIN (1997) afirma que os seres humanos vêm transpondo a fronteira da crença de que os conhecimentos dos eventos previstos estão sob o domínio obscuro de oráculos e adivinhos e, que não basta acreditar que o futuro é um espelho do passado. Pode-se afirmar que o risco é inerente a qualquer atividade, na vida pessoal, profissional ou nas organizações e pode envolver perdas, bem como oportunidades e que, a atitude diante do risco é uma prerrogativa individual. A atitude diante do risco supõe a consideração da atitude diante da incerteza e da perda potencial e da expectativa de ganho na situação. Neste cenário torna-se imprescindível apropriar-se de técnicas de análise e gerenciamento de riscos para o sucesso de qualquer empreendimento.

O objetivo deste trabalho é de propor a prática sustentada do desempenho da logística, promovendo segurança das suas operações, nos diversos níveis da cadeia produtiva. Assim sendo, o framework proposto neste artigo visa ser uma ferramenta para análise qualitativa dos riscos das organizações aplicada à sustentabilidade das operações logísticas.

Nas próximas seções temos o gerenciamento de riscos logísticos, a tipificação para o gerenciamento dos riscos orgânicos, o framework dos riscos orgânicos aplicados à logística e a conclusão

\section{O GERENCIAMENTO DOS RISCOS LOGÍSTICOS}

Empreender significa buscar um retorno econômico-financeiro adequado ao nível de risco associado à atividade. Ou seja, o risco é inerente à atividade de negócios, onde a consciência do risco e a capacidade de administrá-lo, aliada à disposição de correr riscos e de tomar decisões, são elementos-chave. Assumir riscos diferencia empresas líderes, mas também pode levar a estrondosos fracassos.

A pesquisa "In the dark" realizada pela DELOITTE and TOUCHE (2007) demonstrou a crescente preocupação com os riscos não financeiros que precisariam ser identificados com rapidez, precisão e confiabilidade pelo alto impacto que podem causar aos negócios. O resultado das iniciativas de negócios revela que o risco pode ser gerenciado a fim de subsidiar os stakeholders na tomada de decisão, visando alcançar objetivos e metas dentro 
do prazo, do custo e das condições pré-estabelecidas. Stakeholders são as partes interessadas: públicos relevantes com interesses pertinentes à organização, ou ainda, indivíduos ou entidades que assumam algum tipo de risco, direto ou indireto, em face da organização. São elas, além dos acionistas, os funcionários, clientes, fornecedores, credores, governos, entre outros.

As normas que serão usadas neste framework são baseadas na International Organization for Standardization (ISO), onde temos a norma ISO 31000, que define o risco como o efeito da incerteza nos objetivos. Já a ISO3010 é uma norma de apoio à ABNT NBR ISO 31000 e fornece orientações sobre a seleção e aplicação de técnicas sistemáticas para o processo de avaliação de riscos. A norma ISO22301 fornece uma estrutura que lhe permite identificar ameaças potenciais à sua organização e constrói a capacidade para lidar com elas. Já a norma 28002 vem com uma série de normas internacionais com característica de integrarse a outras normas da ISO como, por exemplo, a ISO 31000. Com o objetivo de prover um processo de auditoria genérico para estabelecer, checar, manter e melhorar o sistema e, intensificar a prevenção, preparação, mitigação, resposta, continuidade e recuperação dos incidentes que produzem ruptura (crise ou desastre) de uma cadeia de suprimentos.

Considerando-se que um efeito é um desvio em relação ao esperado, seja ele positivo ou negativo. Desta forma, sob a ótica da moderna gestão corporativa, o risco é o evento futuro identificado, ao qual é possível associar uma probabilidade de ocorrência, assim como a incerteza é o evento futuro identificado, ao qual não é possível associar uma probabilidade de ocorrência. De outro modo a ignorância refere-se a eventos futuros que, no momento da análise, não poderão sequer ser identificados, muito menos quantificados, como por exemplo, eventos decorrentes de sistemas complexos como o climático. A gestão do risco consiste em obter informações qualificadas para conhecer melhor a situação de risco e/ou intervir nela, tendo como resultado a melhoria da qualidade das decisões nesta situação, com possibilidade de perda ou dano.

A identificação e a tipificação são os primeiros passos para a análise dos riscos a serem oportunamente mensurados e gerenciados por metodologias adequadas às estratégias, táticas ou operações dos empreendimentos e especialmente nas suas operações logísticas.

\subsection{TIPIFICAÇÃO PARA O GERENCIAMENTO DOS RISCOS ORGÂNICOS}

SALLES JUNIOR (2006) referencia o modelo do PMBOK guide (2004) do Project Management Institute (PMI) como bastante preciso, pois comunica uma importante quebra de paradigma quando aborda riscos de efeitos negativos e positivos. Para o PMI o risco é "um evento ou condição incerta que, se ocorrer, provocará um efeito positivo ou negativo nos objetivos do projeto".

Para STEINER NETO (1998), os componentes da perda potencial ou componentes negativas do risco são: magnitude, chance de ocorrência e grau de exposição. Os elementos determinantes da perda numa situação com risco são: a impossibilidade de dominar as forças naturais, o comportamento humano (livre arbítrio, ações e atitudes individuais e coletivas etc.) e os recursos limitados (tempo, capital etc.) e a informação incompleta, podendo ela ser inadequada, não confiável, não familiar, imprevisível ou inacessível.

A ALARYS (2004) define o risco de incerteza como aquele associado a eventos que ao se materializarem podem ter três tipos de resultados possíveis: "perda, nem perda nem ganho e ganho". Esta definição se enquadra dentro da classificação de "risco especulativo" da teoria clássica de riscos. Como as incertezas podem ter tanto consequências negativas, quanto positivas, ela configura natureza dupla do risco: impactos positivos ou negativos sobre os resultados do projeto. Isto se dá porque cada atividade tem um benefício e/ou uma utilidade que são percebidos de modo diferente por pessoas diferentes, em momentos diferentes. $\mathrm{O}$ mesmo resultado pode ser mais útil para uma pessoa do que para outra. Ele pode ser mais valorizado por uma pessoa do que para outra. Este valor pode ser tangível ou intangível, explícito ou implícito. Da mesma forma, alerta SALLES JUNIOR (2006), que o valor 
associado ao evento de risco pode ser tangível e mensurável, ou não. Devem-se também considerar aspectos intangíveis no processo de tomada de decisão relativo a riscos. Para tanto, há que se compreender os três componentes dos riscos: o evento em si: onde de ser identificada a causa raiz (fonte) do risco, bem como seu efeito (consequência);uma probabilidade associada e um impacto no projeto. Quando não controlamos as causas do risco é comum utilizarmos uma forma de transferência contratando apólices de seguros. Esta ação sobre os efeitos ou sinistros são transferidos para uma seguradora, conforme identificado no framework da Figura 1.

A recomendação do IBGC (2007), para determinar o perfil de riscos de uma organização é que são necessárias definições claras de indicadores de desempenho e índices de volatilidade divididos em dois grupos: um de natureza financeira (valor de mercado, geração de caixa operacional, distribuição de dividendos, etc.) e outro de natureza qualitativa (transparência, idoneidade, reconhecimento de marca, ambiente de trabalho e responsabilidade socioambiental, etc.).

Segundo MIRABAL (2004), nas empresas cujos objetivos não são financeiros (entidades governamentais ou sem fins lucrativos, etc.), a diminuição da volatilidade não se atem apenas ao controle do fluxo de caixa, mas se traduz em poder garantir os fundos necessários (orçamentos, etc.) e as operações com a finalidade de poder cumprir as atividades foco de seus objetivos como instituição. O portfólio de riscos por ele definido é constituído pelos riscos de Propriedades, de Pessoas, de Responsabilidade Civil e do Benefício Bruto. No caso do portfólio de riscos integrados, este estaria composto, além dos riscos anteriormente mencionados, pelo resto do grupo de riscos que estão associados aos eventos capazes de gerar inconsistências potenciais ou desvios dos resultados esperados.

A ALARYS (2004) classifica os riscos de acidentes ou riscos puros, riscos de incertezas ou riscos especulativos. Os componentes de avaliação dos riscos empregados por ela consideram elementos como a medida qualitativa, a distância da exposição, os elementos expostos e o perigo. Utiliza como elemento quantitativo a frequência, quantas vezes o fato ocorre (dia, mês e ano) e a probabilidade, seja na concepção frequencista, onde são avaliados o número de eventos num período de tempo ou, na concepção clássica, que considera o número de eventos totais. A avaliação das consequências visa identificar o grau de severidade do evento.

A Norma de Gestão de Riscos da Federation of European Risk Management (FERMA) (2012) estabelece que a identificação dos riscos tenha como objetivo revelar a exposição de uma organização ao elemento de incerteza. Reconhece que esta identificação exige um conhecimento profundo da organização, do mercado no qual esta desenvolve a sua atividade, do ambiente jurídico, social, político e cultural onde está inserida, assim como o desenvolvimento de uma sólida interpretação das suas estratégias e objetivos operacionais, incluindo os fatores fundamentais para o seu êxito, as ameaças e oportunidades relativas à obtenção dos referidos objetivos.

A Asociación Latinoamericana de Administradores de Riesgos y Seguros (ALARYS) (2004) classifica a gestão das incertezas como do tipo amplo, onde se manuseiam tanto os cenários positivos como os negativos dos eventos a que está exposta a organização e, do tipo restrito, onde se manuseiam somente os cenários de resultados negativos.

O estudo da ELO Group (2007) identificou que vem sendo pouco debatido que as mesmas fontes de incertezas, causadoras de novas ameaças e destruidoras de valor para os acionistas, são também geradoras de uma vasta gama de oportunidades potenciais e opções de inovação para as organizações. Desta forma, aparentemente há um desequilíbrio entra a atenção e esforços investidos em gestão de riscos para prevenção de ameaças em detrimento a gestão de riscos para exploração de oportunidades.

Um aspecto importante na definição da estratégia de uma organização é seu apetite ao risco. Que nível de risco a organização pode aceitar na busca e realização de sua missão é definido pela tolerância ao risco. A HSE (2001) demonstra num modelo aplicado à gestão de 
riscos em que o apetite ao risco é avaliado numa análise, ex-ante. Já a tolerância é definida pelo nível aceitável de variabilidade na realização das metas e objetivos definidos e, seu índice é identificado pelo monitoramento, sendo uma análise ex-post.

SALLES JUNIOR (2006) destaca que cada pessoa reage de modo diferente ao mesmo estímulo ou uma mesma situação de risco. Porém, todas as pessoas tomadoras de decisão, tendem a maximizar o seu proveito e a sua satisfação, mas isso é feito de forma diferente para cada pessoa e em distintos graus de valorização. Os seres humanos têm diferentes graus de atração ou exposição aos riscos. As pessoas têm também diferentes graus de crença na repetição de padrões de comportamento do passado. Qualquer evento é absolutamente singular e qualquer modelo de representação do risco é uma representação parcial da realidade. Pessoas diferentes realizam aproximações da realidade por diferentes meios a partir de diferentes graus de informação. Cada pessoa reagirá de modo diferente da outra, em face de uma situação de incerteza. Assim, de forma geral existem características distintas de pessoas frente aos riscos: as tomadoras de riscos (risk takers) e as avessas ao risco.

A partir das diversas abordagens e afirmações apresentadas podemos inferir que o desafio do gerenciamento dos riscos é atuar de forma pró ativa em relação ás incertezas e equilibrar o emprego de fatores qualitativos com os quantitativos. Foi também identificado que o risco é inerente a qualquer atividade humana convivendo permanentemente com riscos de toda natureza, dimensão e efeitos que tanto podem ser negativos quanto positivos.

Segundo ROSEMANN, M. e ELO GROUP (2009) existe uma necessidade para desenvolver arquiteturas técnicas para riscos - isto é, a interação de todos os sistemas de gestão de riscos em uma única solução abrangente e orgânica. Isso ainda não tem sido abordado suficientemente na literatura.

É portanto, este o objetivo do framework: auxiliar os gestores a identificar e qualificar o seu posicionamento frente aos riscos e, futuramente, selecionar e integrar as técnicas para o gerenciamento abrangente dos riscos que sejam orgânicos ás atividades das cadeias de suprimento.

\section{O FRAMEWORK DOS RISCOS ORGÂNICOS APLICADOS Á LOGÍSTICA}

Para a constituição do framework contido na Figura 1 considerou-se que as atividades e decisões podem ser classificadas de várias formas e que de acordo com a FERMA (2012) podem ser:

- Estratégicas: Estão relacionadas com os objetivos estratégicos da organização em longo prazo. Podem ser afetadas por áreas como disponibilidade de capital, riscos de soberania e políticos, alterações jurídicas e regulamentares, reputação e alteração ao meio ambiente físico.

- Operacionais: Estão relacionadas com os assuntos quotidianos com os quais a organização é confrontada quando se esforça para atingir os seus objetivos estratégicos.

- Financeiras: Estão relacionadas com a gestão e controle eficazes dos meios financeiros da organização e com os efeitos de fatores externos como, por exemplo, disponibilidade de crédito, taxas de câmbio, movimento das taxas de juros e outros tipos de orientações do mercado.

- Gestão do conhecimento: Estão relacionadas com a gestão e o controle eficazes dos recursos do conhecimento e com a produção, proteção e comunicação destes. Esta categoria engloba fatores externos como a utilização não autorizada ou abusiva da propriedade intelectual, as falhas de energia na zona e tecnologia competitiva. Do lado dos fatores internos podem referir-se avarias nos sistemas ou a perda de funcionários chave.

- Conformidade (Compliance): Estão relacionadas com temas como saúde e segurança, meio ambiente, práticas comerciais, proteção do consumidor, dos dados, assuntos regulamentares e legislação laboral. Apesar da identificação dos riscos poder ser realizada por consultores externos, uma abordagem interna com processos e ferramentas bem comunicados, 
consistentes e coordenados será provavelmente mais eficaz. É essencial que sejam os atores internos os 'proprietários' do processo de gestão de risco.

Segundo HEAD (2009) a Gerencia de Riscos é "a atividade que planeja, organiza, gerencia e controla os processos e os recursos (humanos, materiais e financeiros) visando minimizar o efeito da materialização dos riscos de eventos indesejáveis, sobre uma organização, ao mínimo custo possível”. Quando a área de gestão de risco operacional consegue desenvolver a capacidade de uma organização em reagir com oportunidade é porque ela desenvolveu competências para avaliar os mecanismos de controle propostos no Gerenciamento de Riscos Orgânicos (GROrg), sendo necessário medir e comparar o potencial efeito econômico se estes não forem implantados e custos da implantação destes mecanismos.

Para análise dos riscos de forma a avaliar as atividades que são orgânicas do empreendimento são propostos mecanismos de controle para o Gerenciamento de Riscos Orgânicos (GROrg). As ferramentas e mecanismos de controle são: APP ou APR - Análise Preliminar de Perigo/Risco; What if - O que aconteceria se; AAF - Análise da Árvore de Falhas ou FTA - Fault Tree Analysis; HAZOP - Estudos de Perigo e Operabilidade (Hazard and Operability Studies); FMEA - Análise do modo e efeito de falha (Failure Mode and Effect Analysis) são utilizados para análise dos riscos puros, ou de efeitos negativos e outras. Para fins de avaliação de desempenho empresarial é necessário medir e comparar o potencial efeito econômico se estes mecanismos de controle não forem implantados, assim como avaliar os custos da implantação destes mecanismos. Para O GROg esta análise econômicofinanceira, utilizando-se também de ferramentas de análise qualitativa, como conformidade (Compliance) ou sustentabilidade, ou quantitativa de riscos está contida no fluxo dos riscos operacionais. Assim, o GROrg é o processo através do qual as organizações analisam metodicamente os riscos inerentes às respectivas atividades, com o objetivo de atingirem uma vantagem sustentada em cada atividade individual e no conjunto de todas as atividades. $\mathrm{O}$ ponto central de uma boa gestão de riscos é a identificação e o processamento dos dados, que se otimiza pelo uso de tecnologia da informação, que permite seu oportuno tratamento (ISACA, 2014). Neste contexto, o seu objetivo é o de agregar valor de forma sustentada a todas as atividades do departamento logístico e coordena a interpretação dos potenciais aspectos positivos e negativos, de todos os fatores que podem afetar as operações da organização. Aumenta a probabilidade de êxito e reduz tanto a probabilidade de fracasso como a incerteza da obtenção de todos os objetivos globais da organização, além de prover ferramentas de decisão para a securitização dos riscos extraordinários.

Desta forma, o GROrg se apresenta como um processo contínuo de desenvolvimento da estratégia logística de uma organização e se aplica como uma ferramenta de estruturação da análise do posicionamento dos gestores de riscos na implantação de suas estratégias organizacionais,. O GOrg aplica-se particularmente na estratégia logística a se considerar o dinamismo dos seus processos de negócios que orientam para a demanda dos mercados aos quais atendem suas operações. O GROrg se propõem a identificar metodicamente todos os riscos inerentes às atividades passadas, presentes e, em especial, futuras de uma cadeia de suprimentos, afim de aproveitar as oportunidades oferecidas pela alavancagem dos riscos positivos e o aproveitamento das suas potencialidades. Para atingir seus objetivos de otimizar os resultados frente aos riscos, GROrg deve estar integrado na cultura da organização com uma política eficaz e um programa conduzido pela direção de topo. O GROrg, representado pelo framework da Figura 1 é um programa repositório de ferramentas para orientar o posicionamento dos gestores para as análise dos riscos e que busca traduzir a estratégia do negócio em objetivos táticos e operacionais, atribuindo responsabilidades na gestão dos riscos ao longo de toda a organização e se estende à sua cadeia produtiva, como parte integrante da respectiva descrição de funções. Esta prática sustenta a responsabilização, a avaliação do desempenho e respectiva recompensa, promovendo desta forma segurança e a eficiência operacional nos diversos níveis da cadeia produtiva, desde os planos estratégicos, até as táticas e protocolos empregados nas operações da logística de distribuição no varejo. 
Tendo a organização avançado de uma estratégia reativa para uma postura pró ativa no gerenciamento de seus riscos logísticos estabelecerá uma visão de agregação de valor. A organização passa a compreender que a atitude do gestor/decisor diante do risco logístico é uma prerrogativa individual em prol da corporação. Assim como, a atitude diante do risco logístico supõe a consideração da atitude diante da incerteza e da perda potencial e da expectativa de ganho da situação.

Desta forma para a finalidade deste trabalho considera-se que o gerenciamento de riscos orgânicos (GRorg) visa complementar estudos em gerenciamento de risco logístico sendo estruturante de sistemas que proveem instrumentos aos administradores, para tornar evidentes aos stakeholders: as potencialidades de êxito empresarial ou exposição dos capitais ao risco logístico. O GROrg deixa de ser um gasto para mitigar danos e passa a ser um investimento das organizações na redução dos custos totais, conforme requisitos para otimização da cadeia logística. Mitiga a ocorrência de perdas e controla as ações de transferências de riscos através de ferramentas de gestão dos riscos das atividades ou operações que lhes são orgânicas, além de promover a sustentabilidade dos negócios pela análise de conformidade muito empregada nos sistemas de Controladoria.

O framework representado na Figura 1 apresenta a estrutura do GROrg, que preconiza a gestão de risco logístico em seu nível operacional, em duas abordagens clássicas que se referem a mitigação por ação securitária, onde se transfere os efeitos dos danos representado pelo sinal (-). Do outro lado, a abordagem financeira, que é baseada em métodos de alavancagem dos riscos na administração de portfólios de investimentos de ativos, está representada pelo sinal (+).

A visão da gestão de riscos estratégicos no GROrg é delineada pelo cumprimento de leis e normas. As incertezas são identificadas e dimensionadas a partir da visão de projeto.

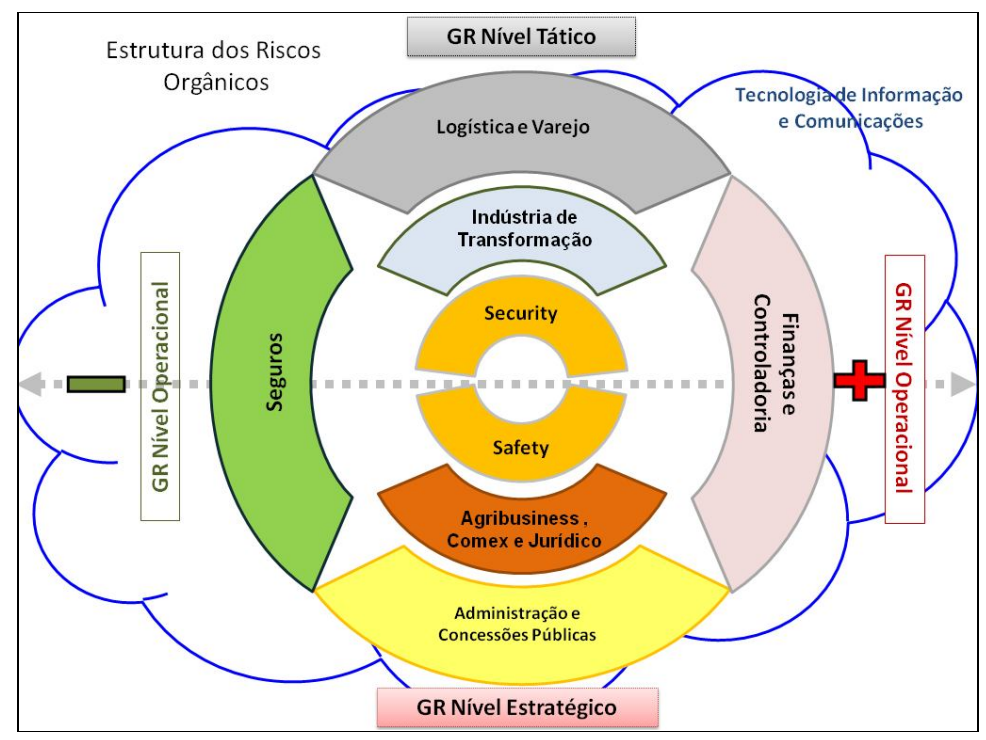

Figura 1 - Framework do Gerenciamento de Riscos Orgânicos

No ambiente da Administração Pública a abordagem do GROrg se pauta pela gestão estratégica das oportunidades e riscos relativos a imagem e da confiança institucional, a fim de garantir a continuidade do projeto. É fortemente influenciada pelos impactos impostos pelos sistemas de controle e tecnologias de informação. Estabelece os modelos de políticas públicas (Regulatória, Tributária ou Fiscal). Existem também oportunidades através de implantação de políticas via Agências Reguladoras. De outro lado exige absoluta conformidade á legislação de licitações e de contratos e, deve atender ás exigências políticas impostas pelos riscos no ambiente social (descaminho, fraudes e corrupção). No campo das 
Concessões Públicas de Infraestrutura, particularmente em sistemas de transportes, energia, telecomunicações, saneamento básico, saúde, segurança pública e defesa civil as avaliações estratégicas dos riscos se dão no âmbito das oportunidades e riscos da gestão da imagem e da confiança institucional. Mas deve considerar os riscos do emprego de Parcerias Público e Privado (PPP), com a instabilidade no sistema regulatório do mercado.

A segunda camada do sistema esférico do GROrg é o meridiano relativo ao risco legal, compreendendo as leis, normas e regulamentações comportando as abordagens relativas a propriedade intelectual, marcas e patentes. A avaliação dos aspectos relativos ás oportunidades e riscos no campo tributário, fiscal, relações trabalhistas e comerciais, além dos impactos relativos aos acordos internacionais e seus sistemas de regulação e arbitragem.

Dentro do espectro de riscos nas operações em negócios internacionais destaca-se o relativo à volatilidade das taxas cambiais e das políticas de comércio internacional. Além das taxas cambiais, o agronegócio brasileiro é fortemente impactado pelos riscos relativos ás barreiras não tarifárias, a sazonalidade da produção, a dependência de recursos naturais e condições meteorológicas, mas também é beneficiado pela percepção de sua contribuição para o meio ambiente com oportunidades no desenvolvimento do mercado de crédito de carbono.

O núcleo do sistema se divide na tradicional divisão dos modelos de segurança, sejam eles sob a ótica do Safety, que se refere na maioria dos casos à proteção das pessoas do perigo: estar livre de situações de risco, ou não oferecer risco para a logística. Apresenta-se com foco no controle de perdas atuando antes dos eventos de sinistros e busca ter capacidade de evitar ou mitigar os danos. Caracteriza-se por ações de prevenção antes dos sinistros. Ultrapassando o limite estabelecido eixo do "equador", está a abordagem Security. Nesta camada da gestão dos riscos logístico estão contidas as medidas e ações contra coisas desagradáveis, perigosas, inesperadas (crimes, riscos patrimoniais). Tem característica reativa por atuarem com precedência após os eventos. Suas competências são relativas à gestão de crises e normalmente tratam das emergências e da resiliência operacional (BLOS e HOEFLICH, 2012).

No meridiano da gestão ambiental se destacam as atividades da indústria de transformação ou atividades econômicas de grande impacto ambiental, como os alguns tipos de fontes de energia não renováveis ou de grande impacto para a sua implantação, como as barragens para hidroelétricas. Dada as dimensões dos projetos há a necessidade da gestão dos riscos relativos aos valores dos investimentos na infraestrutura dos projetos, além dos aspectos relativos á imagem das empresas e organizações envolvidas e considerações sobre o ambiente regulatório do mercado.

No meridiano superior do sistema encontram-se as atividades econômicas fortemente impactadas pela demanda. A gestão da cadeia logística de suprimentos é o modelo que se assemelha aos dos riscos neste setor de atividades. A decisão fundamental é relativa à decisão de realizar internamente a gestão dos riscos (fazer), ou transferir os riscos (comprar). Os modelos de decisão vão desde transferências dos riscos por meio de contratos de serviços até via apólices específicas de seguros. A mesma abordagem se dá nas atividades do varejo, onde a gestão do risco de crédito pode ser própria ou transferida para o sistema financeiro. A gestão dos riscos é orientada para a gestão da imagem das organizações, sendo a decisão inicial a mesma da logística: realizar a gestão internamente ou terceirizar (fazer x comprar). No nível tático o GROrg identifica quatro características para a avaliação dos riscos que passam a ser mais orientados pela demanda. A área de logística é tomadora de risco, que é percebido como oportunidade, e passa a ser pouco limitada pelos protocolos normativos ou de segurança.

O eixo do "equador", representado pela linha pontilhada, se sustenta em duas estruturas fundamentais dos riscos operacionais. De um lado, no campo da controladoria (finanças) estão contidos os elementos de decisão sobre investimentos em ativos, dos mercados financeiros via os seus derivativos, os já citados riscos de créditos e os modelos de conformidade (compliance) baseados nos acordos internacionais relativos aos riscos contábeis. Os modelos de riscos operacionais no campo financeiro são normalmente 
alavancadores de riscos (+), sendo apenas contidos pelos limites do compliance, exigido nos sistemas contábeis. Do outro lado do eixo, está a estrutura suporte baseada em securitização dos riscos (-). É o espelho da estrutura operacional baseada em transferência dos riscos nas cadeias logísticas.

Especificamente no Brasil o aspecto Safety é comumente aplicado á segurança das pessoas nas atividades laborais, tendo-se como agravante os aspectos éticos, morais e consequências sociais inerentes e decorrentes dos acidentes no trabalho. Como a adoção de providencias preventiva está associada à aplicação de recursos financeiros, essa gestão tem o ônus adicional de questionamentos de ordem humanitária. Assim, a constatação de que um acidente poderia ter sido evitado, remete a que qualquer acidente pode e deve ser evitado. Ao contraporem-se custos com sentimentos, estabelece-se um desafio para o gestor, que pode, evidentemente, ter implicações pessoais e legais graves. Desta forma deve-se empregar a estratégia ex-post de substituir o binômio diagnóstico/remediação por prognóstico/prevenção. Esta discussão traz a luz comportamentos que consideram a redução de custos com o aumento controlado de riscos, o que pode escamotear intenções de apenas reduzir custos. Condutas de risco podem trazer resultados em sentido inverso aos ganhos pretendidos.

De outro lado, considerando os atributos de serviços logísticos de CAVANCATI NETTO e HOEFLICH (2005) os aspectos relativos à segurança patrimonial (Security) tem seus riscos medidos a partir do histórico de perdas e avarias das cargas e ativos patrimoniais, cuja amplitude de proteção se percebe a partir do emprego de sistemas de monitoramento com o uso de Circuito Fechado de Televisão (CFTV), sensores de presença com alarmes de invasão e de combate a incêndios, para proteção dos ativos patrimoniais.

A análise de sistemas complexos como o apresentado no framework da Figura 1, se enriquece, ao considerar seus aspectos interdependentes e interativos. LEFF (2000) recomenda "fundir as condições teóricas para a produção de conhecimentos interdisciplinares sobre os processos materiais que convergem em sistemas socioambientais complexos (interdisciplinaridade teórica), com a aplicação e integração de um conjunto de saberes técnicos e práticos no processo de planejamento e gestão (interdisciplinaridade técnica)".

O GROrg se alinha ao conceito do Gestão dos Processos de Negócio (Business Process Management BPM) de que a direção principal dos objetivos da organização e suas estratégias chave devem estar baseadas na proposição do valor dos produtos e serviços entregues aos clientes. Este conceito de gestão dos processos de negócio (BPM) está intimamente alinhado com as práticas na gstão das operações logísticas e seus riscos orgânicos.

O framework orientado para controle contábeis da Committee of Sponsoring Organizations of the Treadway Commission (COSO) foi desenvolvido para a gestão de riscos empresariais e controles internos com vistas a melhoria do desempenho das organizações, sendo suas orientações técnicas direcionadas para controles internos e, assim se apresentam pouco sensíveis às mudanças drásticas de demandas ou rupturas da cadeia logística durante a implantação da estratégia organizacional.

Quanto à governança efetiva para que a Tecnologia da Informação seja suporte às metas de negócios, otimize os investimentos da empresa e gerencie adequadamente os riscos e oportunidades correspondentes à TI, o GROrg segue os princípios preconizados pelo COBIT (ISACA, 2014).

Como exemplo de uma ferramenta operacional para a análise qualitativa dos riscos na logística de distribuição, o GROrg identifica o requisitos da Transport Asset Protection Association (TAPA) para o estabelecimento de padrões mínimos para as melhores práticas de segurança de instalações de armazenamento, manuseio e movimentação dos ativos nos modais de transportes terrestre e aéreo. Além de orientar os requisitos para o modal rodoviário, estas normas também foram estabelecidas para garantir os padrões mínimos do transporte seguro de carga aérea, dentro ou fora de aeroportos. Os requisitos de processo 
compreendem as ameaças à carga seja por roubo, ou o seu uso para fins terroristas. Para atender aos mesmos objetivos no modal aquaviário o Código de Segurança de Navios e Instalações Portuárias (International Ship and Port Facility Security Code -ISPS Code) é referência com o seu conjunto abrangente de medidas para reforçar a segurança de navios e instalações portuárias, desenvolvidos em resposta às ameaças terroristas percebidas á estas instalações e veículos de transporte.

\section{CONCLUSÃO}

A principal fronteira para gestão dos riscos é a prática sustentada na responsabilização com a avaliação do desempenho e respectiva recompensa, promovendo desta forma a segurança e a efetividade operacional nos diversos níveis da organização e da cadeia de suprimentos em que está inserida.

O objetivo do framework é ser útil como metodologia de análise qualitativa e de integração das ferramentas de gerenciamento de riscos, agregar valor de forma sustentada a todas as atividades organizacionais, e particularmente aos controles dos processos das cadeias de suprimentos. O gerenciamento de riscos orgânicos está estruturado em 8 (oito) setores imersos em um ambiente de tecnológico da informação e da comunicação, orientado nos eixos operacional e tático estratégico e contido no framework da Figura 1 sendo o processo através do qual os gestores de riscos logísticos podem analisar metodicamente os riscos inerentes às respectivas atividades nas suas organizações. Tem com o objetivo prover aos gestores de risco uma vantagem sustentada em cada atividade individual e no conjunto de todas as atividades, particularmente nas diversas cadeias de suprimento. O GOrg tem como diferencial ser o mapa do caminho para o posicionamento do gestores e das organizações para a análise de seus riscos logísticos, sejam eles estratégicos, táticos ou operacionais. Se aplica na gestão de riscos das cadeias de suprimentos, por permitir a incorporação das mais diversas ferramentas utilizadas na gestão dos riscos empresariais, tais como as normas ISO e a metodologia COSO, mas com enfoque nos processos logísticos.

Definir os índices de fraude e corrupção, identificar o grau de tolerância ou o nível de apetite ao risco para cada ramo de atividade logística e balancear a aplicação dos aspectos relativos aos riscos positivos, com os tradicionais riscos negativos, ou puros. Em trabalhos futuros cumpre também desenvolver uma metodologia de análise relativa aos riscos orgânicos considerando o ambiente tecnológico atual. $\mathrm{O}$ advento da Internet das coisas, cuja metodologia está embrionária no Sistema de Identificação, Rastreamento e Autenticação de Mercadorias, denominado Brasil-ID, irá intensificar ainda mais o uso de processamento dos dados na nuvem de tecnologia da informação, particularmente nas atividades de monitoramento do fluxo de mercadorias e veículos na cadeia de suprimentos. Esta inovação tecnológica irá aumentar a demanda do adequado tratamento risco, particularmente os relativos á privacidade dos usuários dos sistemas de informação.

Assim, é também objetivo da metodologia de GROrg prover ferramentas de decisão para a securitização dos riscos logísticos e extraordinários. O gerenciamento de riscos orgânicos deve estar integrado na cultura da organização com uma política eficaz e um programa conduzido pela direção de topo e traduzir a estratégia em objetivos táticos e operacionais, atribuindo responsabilidades na gestão dos riscos por toda a cadeia logística.

O desafio do GROrg é delimitar a integração das ferramentas de gerenciamento de riscos identificadas para o apoio à decisão e aplicá-las de forma integrada ás operações logísticas. Assim, a proposta para futuras pesquisas é identificar as ferramentas aplicáveis

para quantificar os aspectos qualitativos dos riscos logísticos, também conhecidos com elementos intangíveis da gestão dos riscos nas cadeias de suprimentos.

\section{REFERÊNCIAS BIBLIOGRÁFICAS}

[1] ALARYS, A Gerência de Riscos como uma Função Organizacional, Revista Administración de Riesgos y Seguros, Revista Alarys, N² 2, 2004. 
[2] ABNT, NBR 31.000: Gestão de riscos - princípios e diretrizes, 2009, 24p.

[3] BLOS, Maurício F. e HOEFLICH, Sérgio Luiz. Supply Chain Resilience Methodology - A General Framework. In: $4^{\text {th }}$ Latin American Conference on Process Safety, 2012, Rio de Janeiro. Instituto de Petróleo, Gás e Biocombustíveis. Rio de Janeiro: CCPS, 2012.

[4] BERNSTEIN, Peter. L., Desafio aos Deuses: a fascinante história do risco, Rio de Janeiro, Elsevier, 1997 - 19ª reimpressão

[5] CAVAlCANTI NETTO, M.A. e HOEFLICH, S. L. Identificação dos atributos de serviços: Etapa inicial para o planejamento da atuação dos Portos Secos na Logística Internacional. In: VIII Simpósio de Pesquisa Operacional e Logística da Marinha CASNAV/RJ, 2005.

[6] DELOITTE and TOUCHE (2007): "Understanding Performance Drivers through the Use of Non-Financial Measurements", Audit Committee Conversations: A Deloitte Academy event, Melbourne, May 2007. Internet: www.deloitte.com (Data de acesso: Março de 2014).

[7] ELO GROUP "Handbook para gestão de Riscos positivos", 2007, Internet: www.elogroup.com.br (Data de acesso: Março de 2014).

[8] FERMA, "Norma de Gestão de riscos", 2003, Internet: www.www.ferma-asso.og (Data de acesso: Março de 2014).

[9] HOUAISS, A., Enciclopédia e Dicionário Ilustrado, Rio de Janeiro, Koogan, 1994.

[10] HEALTH \& SAFETY EXECUTIVE, Reducing risks, protecting people, HSE's decision-making process, HSE Books, England, 2001.

[11] IBGC, Guia de orientação para o gerenciamento de riscos corporativos, 2007. (Data de acesso: Março de 2014).

[12] IMO, "Amendments to the guidelines for formal safety assessment (FSA) for use in the IMO rule-making process - MSC-MEPC.2/Circ.5, 16 October 2006" Internet: www.imo.org.br (Data de acesso: Março de 2014).

[13] IMO, "Código Internacional para a Proteção de Navios e Instalações Portuárias(ISPSCODE)" www.ccaimo.mar.mil.br/convencoes_e_codigos/codigos/isps (Data de acesso: Março de 2014).

[14] KATHERINE BAICKER, David Cutler and Zirui Song. 2010."Workplace Wellness Programs Can Generate Savings." Health Affairs 29 (2):304-311

[15] LEFF E. Pensamento sociológico, racionalidade ambiental e transformações do conhecimento, pp. 109-157. In E Leff. Epistemologia ambiental. Cortez Editora, São Paulo, 2000.

[16] MIRABAL, J., Em direção à Gerência Integral de Riscos (Enterpise Risk Mangement), Revista Administración de Riesgos y Seguros, Revista Alarys, N² 2, 2004.

[17] PIEPER, J. . Virtudes fundamentais. Tradução de Narino e Silva e Beckert da Assumpção, Lisboa, Coleção Éfeso: Aster, 1960.

[18] SALLES JUNIOR, Carlos A. C.; SOLER, A. M.; DO VALLE, J. A. S.; RABECHINI JUNIOR, R., Gerenciamento de Riscos em Projetos, Rio de Janeiro, FGV - Publicações FGV Management, 2006.

[19] ROSEMANN, M. e ELO GROUP "Gestão de riscos de processos de negócio, compliance e controles internos: uma Agenda de pesquisa", 2009, Internet: www.elogroup.com.br (Data de acesso: Março de 2014). 
[20] STEINER NETO, P. J. , A percepção dos resultados esperados pelos beneficiários como fator de influência no processo decisório" , Tese de Dr., Departamento de Administração da Faculdade de Economia, Administração e Contabilidade da USP, 1998.

[21] Internet: www.isaca.org, COBIT 5: A Business Framework for the Governance and Management of Enterprise IT, (Data de acesso: Março de 2014).

[22] Internet: www.brasil-id.org.br: Sistema de Identificação, Rastreamento e Autenticação de Mercadorias, nominado como Brasil-ID, Data de acesso: Março de 2014).

[23] Internet: www.iso.org.br, Data de acesso: Março de 2014.

[24] Internet: www.coso.org Data de acesso: Março de 2014. 